\title{
LXXXIX. On the visible solar and lunar eclipses which will happen in the year 1823, as calculated for Greenwich and Aberdeen; the elements being calculated from the tables of M. Delambre and $M$. Burckhardt
}

\section{Mr. George Innes}

To cite this article: Mr. George Innes (1822) LXXXIX. On the visible solar and lunar eclipses which will happen in the year 1823, as calculated for Greenwich and Aberdeen; the elements being calculated from the tables of M. Delambre and M. Burckhardt, Philosophical Magazine Series 1, 60:296, 440-445, DOI: 10.1080/14786442208644242

To link to this article: http://dx.doi.org/10.1080/14786442208644242

曲 Published online: 29 Jul 2009.

Submit your article to this journal ๘

山ll Article views: 2

View related articles $\sqsubset$ 
From the foregoing observations and experiments it may, therefore, be inferred,

1st. That there is no mercury, or mercurial salt, in the waters of the ocean.

$2 \mathrm{dly}$. That sea-water contains no nitrates.

3 dly. That it contains sal-ammoniac.

4thly. That it holds carbonate of lime in solution.

5thly. That it contains no muriate of lime.

6thly. That it contains a triple sulphate of magnesia and potash.

Some of these circumstances will, of course, require that former analyses of sea-water, and my own in particular, should be corrected and revised; but this I shall not attempt to do, until I have obtained further and still more precise information on the subject.

Harley-street, June 20, 1822.

LXXXIX. On the visible Solar and Lunar Eclipses rohich will happen in the Year 1823, as calculated for Greenwich and Aberdeen; the Elements being calculated from the Tables of $M$. Delanime and $M$. Burckhardt. By Mr. George INNes *.

[The times are inserted according to civil account, the day being reckoned to begin at midnight.]

To the Editors of the Philosophical Magazine and Journal.

Gentremen, - IN calculating the two lunar eclipses, I have increased the moon's equatorial parallax $\frac{1}{6} 0$ part for the refraction of the earth's atmosphere. Astrononers seem doubtful how much is to be added to the semidiameter of the shadow of the eartl as projected at the distance of the moon; but the quantity must certainly bear some proportion to the parallax.

I send you the elements of the solar eclipse, for the use of such as may wish to make a projection; but firom the instant of greatest obscuration falling between 5 and 6 o'clock, it will be found very difficult to determine with sufficient accuracy the distance of the corresponding points on the respective paths.

In reference to this eclipse, it will be interesting to observe whether any visible impression is made on the sun's limb at those places which are situated about the extremity of the penumbra. Such places will be found a little to the west, southwest, and south of London.

* Communicated by the Author. 
The elements of the solar eclipse are as follow:

D. $\mathrm{H}$.

Mean time of ecliptic conjunction at Greenwich. . . . . . .

Equation of mean to apparent time $\}$ at conjunction

July $8 \quad 6$

44. 46,17

Hence the apparent time of conjunction is $\begin{array}{rrrr}8 & 6 & 40 & 16,18\end{array}$

Longitude of the sun and moon from true equinox .....

Sun's right ascension $\cdot \cdot \bullet^{\cdot} \cdot \bullet^{\cdot} \cdot$.

— declination north decreasing. .

- horary motion in longitude : . right ascension declination. .

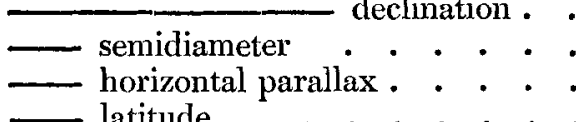

Horary increase of the equation of time

Obliquity of the ecliptic

Moon's latitude north decreasing . .

—_ equatorial horizontal parallax horizontal semidiameter. .

- horary motion in longitude at conjunction . . . . . . horary motion in longitude for the hour preceding . ..$\}$

horary motion for the hour following . . . . . 0 at conjury motion in latitude junction $: \cdot \cdot \cdot \dot{\}}$ horary motion in latitude for the hour preceding . . . horary motion in latitude for the hour following . . . .

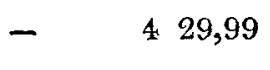

.

$10514 \quad 14,74$

$\begin{array}{lll}106 & 32 & 19,62\end{array}$

$\begin{array}{lll}22 & 35 & 30,6\end{array}$

223,00

223,93

- $\quad 16,10$

1545,57 .

8,65

0,03

$+$

0,396

$\begin{array}{llll}23 & 27 & 49,76\end{array}$

$\begin{array}{lll}1 & 8 & 42,77\end{array}$

$1 \quad 121,15$

1642,12

3759,971

$38 \quad 0,072$

3759,871

325,886

325,610

326,162

$\begin{array}{lll}5 & 50 & 12,5\end{array}$

$35 \quad 43,78$

Angle of the relative orbit with the the sun in the relative orbit . $\}$

The following are the results which $I$ have obtained in calculating for Greenwich and Aberdeen.

Vol. 60. No. 296. Dec. 1822. 


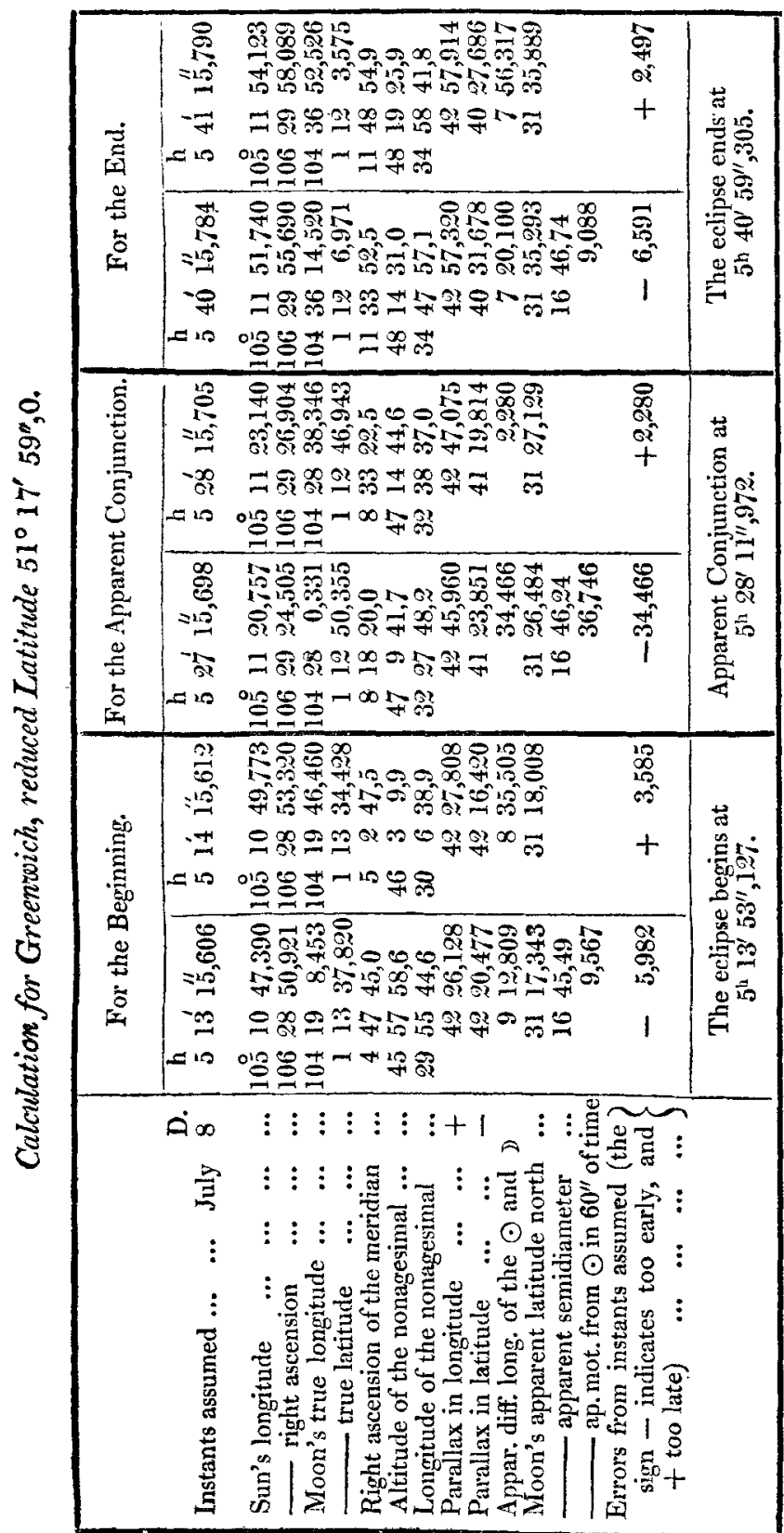

Calculation 
which will happen in the Year 1823.

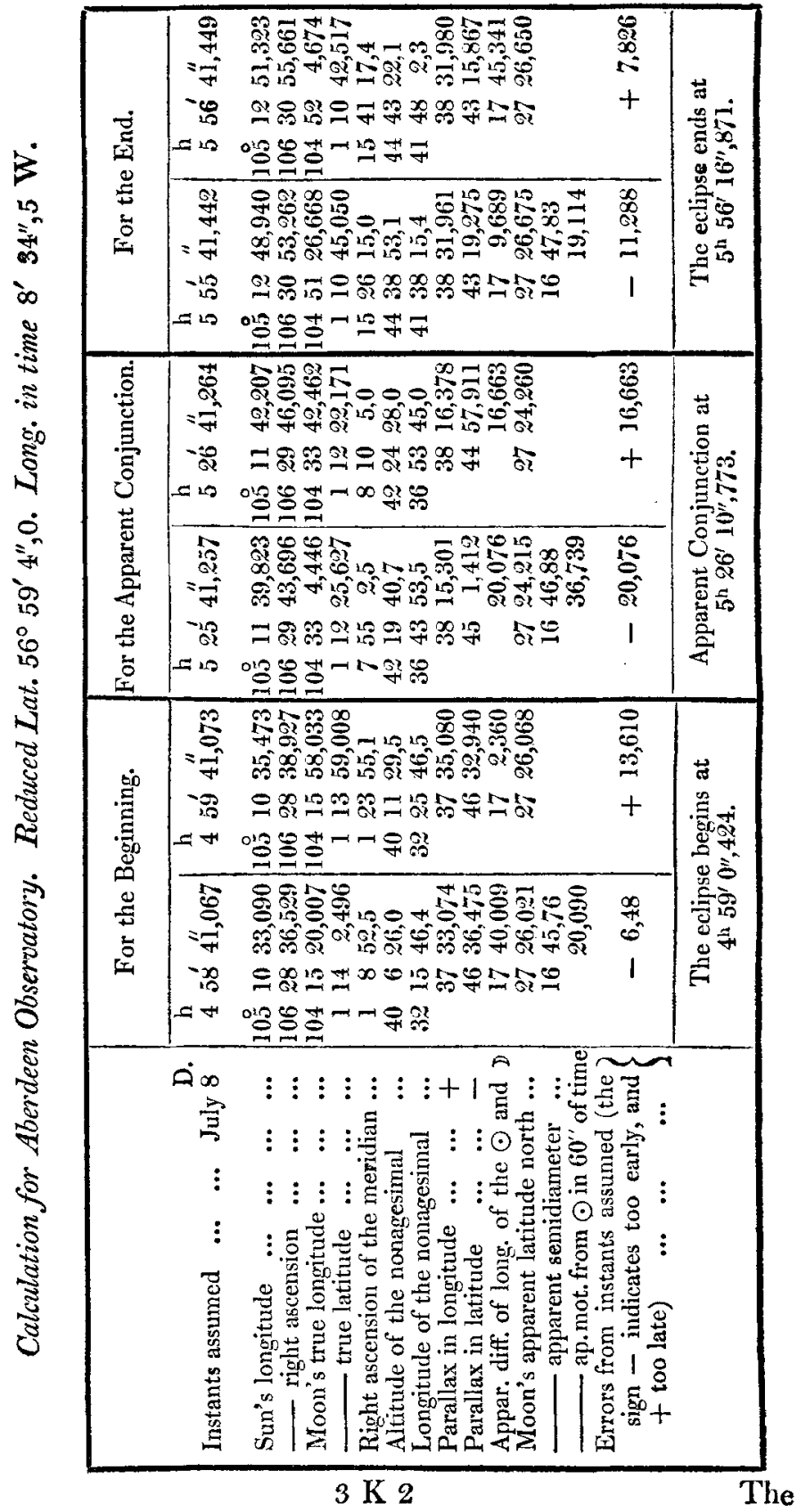


The final results of the calculations are as follow:

\title{
Greenwich.
}

\author{
Apparent time.
}

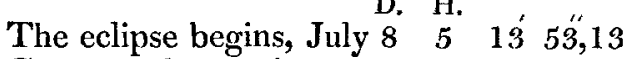

Greatest obscuration $\quad \ldots \quad 5 \quad 27 \quad 20,61$

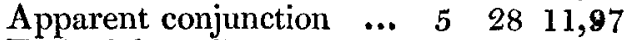

\begin{tabular}{llllll|lll} 
End of the eclipse $\ldots$ & $\ldots$ & $\ldots$ & 5 & 40 & 59,31 & 5 & 45 & 28,90
\end{tabular}

Digits eclipsed, Dig. 0451,16 , on the north part of the sun's disc.-The moon will make the first impression on the sun's limb at $28 \frac{3}{4}^{\circ}$ to the left of his zenith.

\section{Aberdeen.}

The eclipse begins, July 8 . $\begin{array}{llll}4 . & 49 & 0,42\end{array}$

Apparent time.

$\begin{array}{llllll}\text { Greatest obscuration } & \ldots & 5 & 26 & 10,77\end{array}$

$\begin{array}{lllll}\text { Apparent conjunction } & \ldots & 5 & 26 & 14,07\end{array}$

$\begin{array}{lllll}\text { End of the eclipse } \ldots & \ldots & 5 & 56 & 16,87\end{array}$

Mean time.

H.

5 18 22,55

$5 \quad 31 \quad 50,13$

$\begin{array}{lll}5 & 32 & 41,49\end{array}$

Digits eclipsed, Dig. $5 \frac{1}{1} 20,56$, on the north part of the sun's disc. - The moon will make the first impression on the sun's limb at $6 \frac{1}{2}^{\circ}$ to the left $*$ of his zenith.

January 26. Moon eclipsed, partly visible.

Greenwich.

AberdeEn.

Apparent time. Mean time. Appar. time. Mean time.

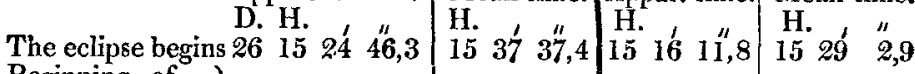
Beginning of total darkness

Mooon rises \begin{tabular}{lll|llr|lll|lll}
16 & 22 & 15,9 & 16 & 35 & 7,6 & 16 & 13 & 41,4 & 16 & 26 & 33,1
\end{tabular}

Eclipticopposition

Middle

End of total darkness.

End of the eclipse Dig. ' \begin{tabular}{lll|lll|lllllll}
16 & 36 & 29,2 & 16 & 49 & 21,0 & 16 & 13 & 19,4 & 16 & 26 & 11,2
\end{tabular}

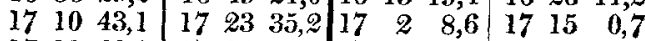
$\begin{array}{lllllllllllll}17 & 11 & 29,3 & 17 & 24 & 21,4 & 17 & 2 & 54,8 & 17 & 15 & 46,9\end{array}$ \begin{tabular}{lll|lll|lll|lll}
18 & 0 & 42,7 & 18 & 13 & 35,2 & 17 & 52 & 8,2 & 18 & 5 & 0,7
\end{tabular} \begin{tabular}{lll|lll|lll|lll}
18 & 58 & 12,3 & 19 & 11 & 5,3 & 18 & 49 & 37,8 & 19 & 2 & 30,8
\end{tabular}

Digits eclipsed 204946,9 from the north side of the earth's shadow.-The moon's centre will pass $4^{\prime} 28^{\prime \prime}, 0$ north of the centre of the earth's shadow, at the middle of the eclipse.

* We presume the author means on the left side when looking through a telescope which inverts the objects.-EDrT. 
July 23. Moon eclipsed, partly visible.

Greenwich. Aberdeen.

\begin{tabular}{|c|c|c|c|c|}
\hline $\begin{array}{r}\text { Appa } \\
\text { The eclipse begins?3 }\end{array}$ & 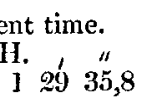 & $\begin{array}{l}\text { Mean time. } \\
\text { H. }{ }^{\prime \prime} \\
13 \tilde{s} 38,5\end{array}$ & 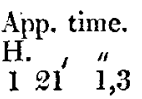 & $\begin{array}{l}\text { Mean time. } \\
\text { H. } 27^{\prime} 4,0 \\
\text { I } 4,0\end{array}$ \\
\hline $\left.\begin{array}{l}\text { Beg. of total } \\
\text { darkness }\end{array}\right\}$ & 23622,6 & $\mathcal{2} 4 \mathcal{2} 25,4$ & 22748,1 & 23350,9 \\
\hline Middle . . & 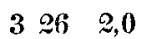 & 332 & $\begin{array}{lll}3 & 17 & 27,5\end{array}$ & $\begin{array}{lll}3 & 23 & 30,4\end{array}$ \\
\hline Ecliptic opposition & 328 & 334 & $\begin{array}{lll}3 & 19 & 28,9\end{array}$ & 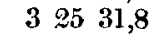 \\
\hline Moon sets & 41 & 47 & 33154,4 & $\begin{array}{lll}3 & 37 & 57,3\end{array}$ \\
\hline $\left.\begin{array}{c}\text { End of total } \\
\text { darkness }\end{array}\right\}$ & $\begin{array}{lll}4 & 15 & 41,4\end{array}$ & $4 \stackrel{21}{44,4}$ & $\begin{array}{lll}4 & 7 & 6,9\end{array}$ & $\begin{array}{lll}4 & 13 & 9,9\end{array}$ \\
\hline End of the eclipse & $5 \stackrel{2}{2} 28,2$ & $\begin{array}{lll}5 & 28 & 31,3\end{array}$ & $\begin{array}{llll}5 & 13 & 53,7\end{array}$ & $\begin{array}{lll}5 & 19 & 56,8\end{array}$ \\
\hline
\end{tabular}

Digits eclipsed $18 \quad 1322,1$ from the north part of the earth's shadow. - The moon's centre will pass $9^{\prime} 10^{\prime \prime}, 9$ north of the centre of the earth's shadow at the middle of the eclipse.

Aberdeen, Nov. 15, 1829.

XC. Some Remarks on Urinary Calculi, and their Chemical Examination. By John Murray, F.L.S. M.G.S. M.W.S. \&.c. \&c.

\section{To the Editors of the Philosophical Magazine and Journal.}

Grentlemen, $\mathbf{T}_{\text {o the combined genius of Berzelius, Marcet, }}$ Henry, Prout, and Brande, we are indebted for almost all we know on the highly interesting subject of urinary calculi.

The existence of calculi composed of lithate of ammonia, had been called in question; but Dr. Prout had since ascertained its existence in one case at least-a young person : and to those of immature age it has hence been presumed confined. For my own part I am of opinion none other exists, except of that description. I have not been fortunate, at least, to meet with any composed of lithic acid; and when we consider the solubility of this acid, I do not think, prima facie, that it is reasonable to expect to meet with it uncombined in a concrete form in urine.

I have drawn my inferences from the numerous examples that have occurred in my chemical examination of these concretions; and must say, that I never met with one that, being mixed with pure caustic potassa, did not yield unequivocal evidence of the escape of ammonia, on bringing a feather dipt in acid near. If the acetic acid was weak, this indication might not appear; but if muriatic or nitric acid was employed, there then remained no doubt of the presence of ammonia. Now what 